\title{
Modeling of electrical conductivity in the proton conductor $\mathrm{Ba}_{0.85} \mathrm{~K}_{0.15} \mathrm{ZrO}_{3-\delta}$
}

\author{
Z. Sherafat ${ }^{1}$, M.H. Paydar ${ }^{1}$, I.Antunes $^{2}$, N.Nasani ${ }^{3}$, A.D.Brandão ${ }^{2}$, D.P.Fagg ${ }^{3 *}$ \\ ${ }^{1}$ Department of Materials Science and Engineering, School of Engineering, Shiraz \\ University, Shiraz, Iran \\ ${ }^{2}$ Department of Materials and Ceramic Engineering, CICECO, University of Aveiro, 3810- \\ 193 Aveiro, Portugal \\ ${ }^{3}$ Nanotechnology Research Division, Centre for Mechanical Technology and Automation, \\ Department of Mechanical Engineering, University of Aveiro, 3810193 Aveiro, Portugal.
}

\begin{abstract}
The electrical conductivity of $\mathrm{Ba}_{0.85} \mathrm{~K}_{0.15} \mathrm{ZrO}_{3-\delta}(\mathrm{BKZ})$ has been studied as a function of both oxygen and water vapor partial pressure in the temperature range of $550-700^{\circ} \mathrm{C}$, to determine the partial conductivities of protons, holes, and oxygen vacancies from the defect model. It is shown that P-type conduction is dominant in dry oxidative atmospheres, while in wet oxidative atmospheres, a conduction transition from proton to hole conduction is found with increasing temperature. On the contrary, in wet nitrogen atmosphere, proton conduction is dominant over the whole temperature range. The calculated activation energies for oxide-ion, electron-hole and proton conduction are $0.86,1.36$ and $0.59 \mathrm{eV}$, respectively. The standard solution enthalpy for water dissolution is $-90 \mathrm{~kJ} / \mathrm{mol}$, which is lower in absolute terms than that typically reported for doped barium cerates but very close to that reported for $\mathrm{BaZr}_{0.85} \mathrm{Y}_{0.15} \mathrm{O}_{3-\delta}$.
\end{abstract}

Keywords: Protonic ceramic; high temperature proton conductor (HTPC); potassium doped barium zirconates; Transport Properties.

1

(C) 2015. This manuscript version is made available under the Elsevier user license http://www.elsevier.com/open-access/userlicense/1.0/ 


\section{Introduction}

Perovskite proton conducting oxides have been widely investigated because of their promising applications in a variety of electrochemical devices such as fuel cells, steam electrolysis, hydrogen pumps and gas sensors [1-4]. Among proton-conducting oxides, barium zirconate has great benefits for such applications because of the combination of excellent chemical stability and high bulk conductivity $[5,6]$. The proton conductivity of these oxides strongly depends on acceptor doping of the material for the creation of oxygen vacancies, which are necessary for proton incorporation by hydration.

The proton incorporation reaction is formally written, in Kroger-Vink notation, as:

$\mathrm{H}_{2} \mathrm{O}(\mathrm{g})+\mathrm{V}_{\mathrm{O}} \ddot{\bullet}+\mathrm{O}_{\mathrm{O}} \times 2 \mathrm{OH}_{\mathrm{O}} ; \mathrm{K}_{\mathrm{w}}=\frac{\left[\mathrm{OH}_{\mathrm{O}}^{\cdot}\right]^{2}}{\left[\mathrm{~V}_{\mathrm{O}}^{*}\right] \mathrm{P}_{\mathrm{H}_{2} \mathrm{O}}}$

where $\mathrm{K}_{\mathrm{w}}$ is the equilibrium constant for hydration.

The basicity of the constituent oxides also affects water uptake capacity $[5,7,8]$, so that doping with highly basic alkali ions may increase levels of hydration and improve proton conductivity. Alkali ions with a significantly greater ionic radius than that of the B-site ion will be preferably located at the A-site of the perovskite to maintain structural stability. Among alkaline ions, potassium is a suitable candidate because of its close ionic radius to barium. Patnaik et al. [9] synthesized and measured the proton conductivity of A-site potassium doped barium zirconates that contained $4 \mathrm{~mol} \% \mathrm{Y}_{2} \mathrm{O}_{3}$ as a secondary acceptor dopant on the B-site and found that potassium doping caused an increase in proton conductivity. Nonetheless, these authors were unable to produce single phase A-site potassium doped barium zirconates without the presence of yttrium by traditional solid state synthesis techniques. More recently, Xu and et al. [10] successfully synthesized similar Asite potassium, B-site yttrium doped barium zirconate with and without Zinc doping and studied the conductivity of the samples in different atmospheres. They introduced a limiting 
range for successful potassium substitution and showed that water uptake and conductivity improved with potassium doping, in agreement with the results of Patnaik et al. [9].

To date, there remain no reports where single phase A-site potassium doped barium zirconates, $\mathrm{Ba}_{1-\mathrm{x}} \mathrm{K}_{\mathrm{x}} \mathrm{ZrO}_{3-\delta}$, have been successfully synthesized and assessed for proton conductivity. In the current work pure A-site potassium doped barium zirconates have been synthesized, without any additives, by mechanosynthesis. This high energy milling technique allows the formation of the pure perovskite phase at room temperature and provides nanometric, homogenous powders of good sinterability that lower the temperature requirement for full densification to $1300^{\circ} \mathrm{C}$. The current article reports the effect of atmosphere on partial conductivities of the pure A-site potassium doped barium zirconate composition $\mathrm{Ba}_{0.85} \mathrm{~K}_{0.15} \mathrm{ZrO}_{3-\delta}$.

Generally, acceptor doped perovskite oxides can often show mixed ionic-electronic conductivity according to the temperature and the atmosphere to which they are applied. In $\mathrm{H}_{2}$ and $\mathrm{H}_{2} \mathrm{O}$ containing atmospheres at low temperatures, proton conductivity can dominate. However, by increasing oxygen pressure, temperature and decreasing water vapor pressure, electron-hole and oxygen conductivity can become dominant. Thus, it is often necessary to determine the partial conductivity due to each type of charge carrier separately, in order to determine the dominant conduction mechanism at the conditions of intended use.

Several methods have been suggested to determine the ionic and electronic transference numbers in mixed conductors. The Electromotive Force (EMF) method has been used to determine the transport number in ionic solids for which the transport number is close to unity. However, major problems occur with this approach if the electronic transport number is appreciable [11]. The EMF technique is also susceptible to errors arising from electrode polarization and advanced techniques, such as the external resistor approach, must be utilized to correct for this potential error $[12,13]$. The ion blocking method pioneered by Hebb [14] 
and Wagner [15] is the most extensively used method for determining very low electronic conductivity of ionic solids and has been detailed by a number of authors [16-19]. In this method, blocking electrodes are used to block the transport of one type of charge carrier to allow determination of the conductivity due to the remaining types of charge carrier. The ion blocking technique, however, must also be used with extreme caution as the electrode reactions at the mixed conductor/ion blocking electrode interface cannot be fully eliminated and have been shown to cause significant error [11].

Another method that can be used with less limitation with respect to previous methods mentioned above, involves measuring the conductivity of the mixed conductor as a function of partial pressure of oxygen over a wide temperature range. In most proton conductors, the defect concentration is controlled mainly by the acceptor dopant concentration. Hence, the ionic conductivity is usually independent of oxygen partial pressure. On the contrary, the electron or electron-hole conductivity varies significantly with oxygen partial pressure with the electronic defect concentration being significantly influenced by small deviations in the material composition with respect to oxygen. Thus, the contributions of ionic and electronic conductivities and transport number as well as the ionic conduction domain can be assessed by measuring the conductivity as a function of oxygen partial pressure and temperature by fitting experimental data to an acceptable defect model [11].

In this study, the conductivity mechanism and defect structure of $\mathrm{Ba}_{0.85} \mathrm{~K}_{0.15} \mathrm{ZrO}_{3-\delta}$ has been investigated by assessment of electrical conductivity in a range of oxygen and water vapor partial pressures by impedance spectroscopy as a function of temperature. By fitting these data to the proposed defect chemistry, transference numbers, and thus, partial and total conductivities at different gas compositions have been calculated.

\section{Experimental}


$\mathrm{Ba}_{0.85} \mathrm{~K}_{0.15} \mathrm{ZrO}_{3-\delta}$ powders were synthesized by mechanosynthesis using calculated amounts of $\mathrm{BaO}_{2}, \mathrm{ZrO}_{2}$ and $\mathrm{KO}_{2}$ powders as raw materials. Here $\mathrm{ZrO}_{2}$ is in metastable tetragonal form prepared by slow alkaline precipitation, as described in a previous publication by the current authors [20]. Mechanosynthesis was carried out in a planetary ball mill, (Retsch PM200), in air, at $650 \mathrm{rpm}$, using tetragonal zirconia vials (Retsch) and balls with diameters of 5 and 10mm (Tosoh Co.). Further information on this technique can be found in references [20,21]. The ball to powder ratio was fixed at 10:1. Milling was performed by a series of 5 min steps with 5 min of interruptions for cooling and to reverse direction of rotation after each interruption. Milling was done up to $480 \mathrm{~min}$, opening the vial after 240 and $420 \mathrm{~min}$ to remove the gaseous product. The formed powders were then pressed into pellets by using isostatic pressure of $450 \mathrm{MPa}$ and sintered at $1300^{\circ} \mathrm{C}$ for $5 \mathrm{hr}$. To minimize potassium evaporation during sintering, pellets were covered with further powder of the same composition plus $10 \%$ excess potassium in small alumina crucible with an alumina cap that was hermetically sealed with ceramic paste (Ceramabond 552, Aremco). Synthesized powders were characterized by using XRD powder diffraction, using a Rigaku Geigerflex diffractometer $\left(\mathrm{CuK} \alpha\right.$ radiation, step width $0.02^{\circ}$, scan rate $\left.0.5^{\circ} / \mathrm{min}\right)$, over the angular range $20-80^{\circ}(2 \theta)$. To determine electrical conductivity, the pellets were painted with Pt paste and fired at $850^{\circ} \mathrm{C}$ for $5 \mathrm{~min}$. The conductivity was measured using impedance analyzer, Electrochemie-Autolab PGSTAT302N, in the frequency range of $0.1 \mathrm{~Hz}-1 \mathrm{MHz}$ with amplitude of $50 \mathrm{mV}$ in the temperature range of $700^{\circ} \mathrm{C}$ to $550^{\circ} \mathrm{C}$ at $50^{\circ} \mathrm{C}$ intervals in the direction of decreasing temperature. In each temperature, conductivity was determined in different pressure of oxygen by mixing various amount of $\mathrm{O}_{2}$ and $\mathrm{N}_{2}$ gas. Humidification was carried out by bubbling gases through water followed by a saturated $\mathrm{KCl}$ solution in contact with solid $\mathrm{KCl}$. To investigate the effect of partial pressure of water, different pressure of water vapor was obtained by mixing fractions of wet and dry gases. Stability was confirmed 
by performing repeated impedance measurements at each temperature. Impedance spectra were fitted using the ZView software (Scribner Associates).

The partial conductivities of each charge carrier were obtained by the method outlined by Lim et al. [22] and Baek [23], based on the following formulas, modified from those originally published by Frade [24], that describe the defect structure of a high temperature proton conductor that contains an acceptor dopant of single negative effective charge; in the current case $\left[\mathrm{K}_{\mathrm{Ba}}{ }^{\prime}\right]$.

$\frac{\sigma_{\mathrm{OH}_{\mathrm{O}}}^{\cdot}}{\sigma_{\mathrm{OH}_{\mathrm{O}}^{*}}^{*}}=\left[\left(1+\frac{\alpha}{\mathrm{P}_{\mathrm{H}_{2} \mathrm{O}}}\right)^{1 / 2}-1\right]\left(\frac{\mathrm{P}_{\mathrm{H}_{2} \mathrm{O}}}{(1+\alpha)^{1 / 2}-1}\right)$

$\frac{\sigma_{\mathrm{V} \ddot{\mathrm{O}}}}{\sigma_{\mathrm{V} \ddot{\mathrm{O}}}^{*}}=\left[\left(1+\frac{\alpha}{\mathrm{P}_{\mathrm{H}_{2} \mathrm{O}}}\right)^{1 / 2}-1\right]^{2}\left(\frac{\mathrm{P}_{\mathrm{H}_{2} \mathrm{O}}}{\alpha}\right)$

$\frac{\sigma_{\mathrm{p}}}{\sigma_{\mathrm{p}}^{*}}=\left[\left(1+\frac{\alpha}{\mathrm{P}_{\mathrm{H}_{2} \mathrm{O}}}\right)^{1 / 2}-1\right]\left(\frac{\mathrm{P}_{\mathrm{H}_{2} \mathrm{O}}}{\alpha}\right)^{1 / 2} \mathrm{P}_{\mathrm{O}_{2}}^{1 / 4}$

where $\sigma_{\mathrm{OH}_{\mathrm{O}}^{*}}^{*}$ is the protonic conductivity at $\mathrm{P}_{\mathrm{H}_{2} \mathrm{O}}=1 \mathrm{~atm}, \sigma_{\mathrm{p}}^{*}$ is the hole conductivity at $\mathrm{P}_{\mathrm{O}_{2}}=1$ atm and $\mathrm{P}_{\mathrm{H}_{2} \mathrm{O}}=0$ atm, $\sigma_{\mathrm{V}_{\mathrm{O}}}^{*}$ is the oxygen ion conductivity when $\mathrm{P}_{\mathrm{H}_{2} \mathrm{O}}=0$ atm and $\alpha$ is a constant determined by the following relationship:

$\alpha=\frac{8\left[K_{\mathrm{Ba}}{ }^{\prime}\right]}{\mathrm{K}_{\mathrm{w}}}$

where $\left[\mathrm{K}_{\mathrm{Ba}}{ }^{\prime}\right]=\frac{\mathrm{x} . \mathrm{N}_{\mathrm{A}}}{\mathrm{V}_{\mathrm{m}}} ; \mathrm{x}$ is the molar acceptor dopant concentration, $\mathrm{N}_{\mathrm{A}}$ is Avogadro's number, and $\mathrm{V}_{\mathrm{m}}$ is the molar volume of the system and $\mathrm{K}_{\mathrm{w}}$ is the equilibrium constant corresponding to hydration $(\mathrm{Eq}(1))$.

The total conductivity is given by the sum of the partial conductivities:

$\sigma_{\mathrm{tot}}=\sigma_{\mathrm{OH}_{\mathrm{O}}}+\sigma_{\mathrm{V}_{\mathrm{O}}}+\sigma_{\mathrm{p}}$

The above equations (Eq. (2) to (4)) highlight that only $\sigma_{\mathrm{p}}$ shows direct dependency on $\mathrm{P}_{\mathrm{O}_{2}}$ and, thus, total conductivity (Eq. (6)) can be represented by:

$\sigma_{\mathrm{tot}}=\mathrm{a}+\mathrm{bP}_{\mathrm{O}_{2}}^{1 / 4}$ 
where $\mathrm{a}=\sigma_{\mathrm{OH}_{\mathrm{O}}}+\sigma_{\mathrm{V}_{\mathrm{O}}}$ and $\mathrm{b}=\sigma_{\mathrm{p}}^{*}\left[\left(1+\frac{\mathrm{P}_{\mathrm{H}_{2} \mathrm{O}}}{\alpha}\right)^{1 / 2}-\left(\frac{\mathrm{P}_{\mathrm{H}_{2} \mathrm{O}}}{\alpha}\right)^{1 / 2}\right]$.

By measuring slopes of plots of $\sigma_{\text {tot }} v_{s} \mathrm{P}_{\mathrm{O}_{2}}^{1 / 4}$ at two different water vapor pressures $\left(\mathrm{P}_{\mathrm{H}_{2} \mathrm{O}, 1}\right.$ and $\mathrm{P}_{\mathrm{H}_{2} \mathrm{O}, 2}, \alpha$ can be determined from the ratio of two slopes as following:

$\frac{\mathrm{b}_{1}}{\mathrm{~b}_{2}}=\frac{\left[\left(1+\frac{\mathrm{P}_{\mathrm{H}_{2} \mathrm{O}, 1}}{\alpha}\right)^{1 / 2}-\left(\frac{\mathrm{P}_{\mathrm{H}_{2} \mathrm{O}, 1}}{\alpha}\right)^{1 / 2}\right]}{\left[\left(1+\frac{\mathrm{P}_{\mathrm{H}_{2} \mathrm{O}, 2}}{\alpha}\right)^{1 / 2}-\left(\frac{\mathrm{P}_{2} \mathrm{O}, 2}{\alpha}\right)^{1 / 2}\right]}$

After determination of $\alpha, \sigma_{\mathrm{p}}^{*}$ and $\mathrm{K}_{\mathrm{w}}$ can be calculated from Eq. (8) and Eq. (5), respectively. From Eqs. (2) and (3), the intercept (a) can be written as:

$\mathrm{a}=\sigma_{\mathrm{OH}_{\mathrm{O}}^{\cdot}}+\sigma_{\mathrm{V}_{\mathrm{O}}^{*}}=\sigma_{\mathrm{OH}_{\mathrm{O}}^{\cdot}}^{*}\left[\left(1+\frac{\alpha}{\mathrm{P}_{\mathrm{H}_{2} \mathrm{O}}}\right)^{1 / 2}-1\right]\left(\frac{\mathrm{P}_{\mathrm{H}_{2} \mathrm{O}}}{(1+\alpha)^{1 / 2}-1}\right)+\sigma_{\mathrm{V}_{\mathrm{O}}^{*}}^{*}\left[\left(1+\frac{\alpha}{\mathrm{P}_{\mathrm{H}_{2} \mathrm{O}}}\right)^{1 / 2}-1\right]^{2}\left(\frac{\mathrm{P}_{\mathrm{H}_{2} \mathrm{O}}}{\alpha}\right)$

Hence, from the intercepts of plots of $\sigma_{\text {tot }} \mathrm{vs}_{\mathrm{O}_{2}}^{1 / 4}$ measured at two different water vapor pressures, the constants $\sigma_{\mathrm{OH}_{\mathrm{O}}^{*}}^{*}$ and $\sigma_{\mathrm{V}_{\mathrm{O}}^{*}}^{*}$ can be determined.

If the constants $\sigma_{\mathrm{OH}_{\mathrm{O}}^{*}}^{*} ; \sigma_{\mathrm{V}_{\mathrm{O}}^{*}}^{*} ; \sigma_{\mathrm{p}}^{*}$ and the value $\alpha$ are known, the partial conductivities and total conductivity can subsequently be calculated $[22,23]$.

\section{Results and Discussion}

\subsection{Phase preparation.}

The X-ray diffraction pattern of the $\mathrm{Ba}_{0.85} \mathrm{~K}_{0.15} \mathrm{ZrO}_{3-\delta}$ sample obtained by room temperature mechanosynthesis is shown in Fig.1a. The pattern confirms the formation of the pure perovskite phase showing broad peaks that can be calculated by the Williamson Hall technique to correspond to a crystallite size in the range $19.85 \mathrm{~nm}$ [25]. Fig.1b shows an Xray powder diffraction pattern of this material after sintering the pelletized powder to $1300^{\circ} \mathrm{C}$ for 5 hrs in a sealed container. The pure perovskite phase is shown to be maintained, while demonstrating an increase in crystallinity. The lattice parameter of the sintered sample is calculated to be, $4.1894 \AA$, a value significantly lower than that of pure $\mathrm{BaZrO}_{3}$. Thus, 
despite the slightly larger $\mathrm{K}^{+}(1.64 \AA)$ cation with respect to $\mathrm{Ba}^{2+}(1.61 \AA)$ [26] the partial substitution of $\mathrm{Ba}$ for $\mathrm{K}$ leads to a decrease in lattice parameter, as previously noted by $\mathrm{Xu}$ et al. [10], and related to unit cell relaxation due to the creation of oxygen vacancies as charge compensating defects. The apparent absence of impurities in Fig. 1b and the drop in lattice parameter with K-doping both suggest that K-volatilisation has been successfully controlled in the current synthesis route, in contrast to that obtained from standard, high temperature, solid state synthesis [9].

The formed ceramic at $1300^{\circ} \mathrm{C}$ shows geometrical density of $92 \%$ that of the theoretical with an average grain size of $87 \mathrm{~nm}$. A SEM micrograph of a fracture surface of the ceramic is shown in Fig.2, supporting these features. Note the recorded density is considerably higher than that achievable for mechanosynthesiesed powders of the yttrium doped analogue $\mathrm{BaZr}_{0.85} \mathrm{Y}_{0.15} \mathrm{O}_{3-\delta}$ under similar conditions, 74\% @ 1300' $\mathrm{C}$ [21], suggesting that $\mathrm{K}$ may be a useful sintering additive. Conversely, grain growth is shown to be low and is equivalent for both compositions [21].

\subsection{Electrical measurements.}

The inset of Fig. 3 shows a typical impedance response measured at low temperature, consisting of a bulk response, observable at high frequency, with capacitance values in the $\mathrm{pF} / \mathrm{cm}^{2}$ range, followed by a partial grain boundary response at lower frequencies. Such impedance spectra were fitted by a series combination of distributed RQ elements, where the fitting parameters extracted for each distributed arc are the resistance value, $\mathrm{R}$, the pseudocapacitance, $\mathrm{Q}$, of the constant phase element and the parameter $\mathrm{n}$ which can be related to the true capacitance by the equation

$\mathrm{C}=\mathrm{R}^{(1-\mathrm{n}) / \mathrm{n}} \mathrm{Q}^{1 / \mathrm{n}}$

The main image of Fig. 3 shows example impedance spectra measured at $450^{\circ} \mathrm{C}$ in wet oxygen and nitrogen atmospheres. At these temperatures, the bulk response becomes 
unresolvable in the frequency window of the experiment and is revealed only as an offset along the real $Z^{\prime}$ axis at the highest frequency. Intermediate frequencies reveal the grain boundary response, with capacitance values in the $\mathrm{pF} \underline{\mathrm{nF} / \mathrm{cm}^{2}}$ range, while lower frequencies show a Warburg diffusion impedance. These impedance responses were, thus, modeled by the equivalent circuit presented in the main image. The total conductivity was taken as the sum of the bulk and grain boundary components.

The temperature dependencies of the total conductivity in oxygen and nitrogen atmospheres at various water vapor pressures are shown in Fig. 4. In an oxygen atmosphere, total conductivity is shown to take its lowest value at intermediate humidities, while in wetter conditions the conductivity returns to a similar value to that obtained in dry conditions. In contrast, in a nitrogen atmosphere, conductivity is shown to monotonously increase with increasing humidity. These tendencies have been previously observed in others works of acceptor doped perovskite proton conductors [22, 27] and explained to be due to the competitive filling of oxygen vacancies by either water vapor (Eq. (1)) or by oxygen; where the latter is described by the following equation [28].

$$
\frac{1}{2} \mathrm{O}_{2}(\mathrm{~g})+\mathrm{V}_{\mathrm{O}} \ddot{\rightarrow} \rightarrow \mathrm{O}_{\mathrm{O}}{ }^{\times}+2 \mathrm{~h}^{\bullet} ; \mathrm{K}_{\mathrm{O}}=\frac{\mathrm{p}^{2}}{\left[\mathrm{v}_{\mathrm{O}}^{*}\right]_{\mathrm{O}_{2}}^{1 / 2}}
$$

In dry, oxidizing conditions the conductivity of zirconate perovskite materials has commonly been shown to be dominated by p-type electronic conduction [28], whereas upon humidification, the number of p-type charge carriers (Eq. (10)) can become depleted by competitive filling of oxygen vacancies by protonic species (Eq. (1)). This scenario would concur with the lower activation energies noted in wet conditions in the current results, which support an increasing protonic contribution under these conditions [22,27]. In more reducing conditions, the level of p-type conduction is lower, due to a depleted hole concentration that results from the low availability of oxygen (Eq. (10)). In such a case, total conductivity is likely to be dominated by protonic conduction, in agreement with the observed monotonous 
increase in conduction with increasing humidity, due to an increasing concentration of protonic charge carriers, as described by Eq. (1). Based on the relative concentrations of ptype and protonic charge carriers, from Eqs. (1) and (10), and their relative mobilities, one can, therefore, potentially describe the experimental tendencies of total conductivity, obtained in Fig. $4[22,28]$. However, in order to investigate these phenomena in more depth, the relative conductivities of holes, oxide-ions and protons are separated in the subsequent section using the experimental method of Lim et al. [22] and Baek [23].

\subsection{Transport properties.}

The plots of total conductivity against $\mathrm{P}_{\mathrm{O}_{2}}^{1 / 4}$ in dry and wet atmospheres are shown in Fig. 5. Excellent linear relationships between $\sigma_{\text {tot }}$ and $\mathrm{P}_{\mathrm{O}_{2}}^{1 / 4}$ indicates that the suggested defect model outlined by Lim et al. [22] and Baek [23] is valid for the current material. The slopes and intercepts of $\sigma_{\text {tot }}$ vs. $\mathrm{P}_{\mathrm{O}_{2}}^{1 / 4}$ obtained by linear fitting are reported in Table.1. Higher gradients and a lower intercepts are observed with decreasing water vapor partial pressure, suggesting, from Eq. (10), that the hole contribution to total conductivity increases, while the ionic contribution decreases with decreasing $\mathrm{pH}_{2} \mathrm{O}$.

By considering the slopes of $\sigma_{\text {tot }}$ vs. $\mathrm{P}_{\mathrm{O}_{2}}^{1 / 4}$ at two different water pressure, $\alpha$ was determined for each temperature and the water uptake equilibrium constant, $\mathrm{K}_{\mathrm{w}}$, was calculated. These values are reported in Table.2. Fig. 6 shows the effect of temperature on the equilibrium constant of hydration. The standard solution enthalpy for water uptake was determined according to the slope of $\ln (\mathrm{K})$ vs. $1000 / \mathrm{T},-90 \mathrm{~kJ} / \mathrm{mol}$, which very close to reported for other similar zirconate materials, such as $\mathrm{BaZr}_{0.85} \mathrm{Y}_{0.15} \mathrm{O}_{3-\delta},-83.4 \mathrm{~kJ} / \mathrm{mol}$ [5]. These values are lower in absolute terms than reported for doped barium cerate analogues $[22,29]$, a factor that is suggested to be related to the higher basicity of the cerate materials [30]. In this respect, the more negative hydration enthalpy shown by the current 
$\mathrm{Ba}_{0.85} \mathrm{~K}_{0.15} \mathrm{ZrO}_{3-\delta}$ material than $\mathrm{BaZr}_{0.85} \mathrm{Y}_{0.15} \mathrm{O}_{3-\delta}$ concurs well with its expected higher basicity [9].

By determination of the constants $\sigma_{\mathrm{OH}_{\mathrm{O}}^{*}}^{*} ; \sigma_{\mathrm{V}_{\mathrm{O}}^{*}}^{*} ; \sigma_{\mathrm{p}}^{*}$; and $\alpha$, reported in Table.2, partial conductivities can be calculated using Eqs. (2) to (4) under different temperatures and atmospheres. Fig. 7 shows partial and total conductivities against water vapor pressure in nitrogen atmosphere at $650^{\circ} \mathrm{C}$. To check the accuracy of using the proposed equations, the experimental data of total conductivity vs. water vapor pressure in nitrogen atmosphere is inserted by points in the graph. It can be seen that the calculated data are in very good agreement with experimental data, emphasizing the validity of the method.

The temperature dependencies of partial conductivities measured in oxygen and nitrogen atmospheres at the water vapor partial pressure of 0.033 atm are shown in Fig. 8. It can be seen that, in a nitrogen atmosphere, proton conductivity is dominant in the whole temperature range. Conversely, in an oxygen atmosphere it is dominant only at temperatures below $600^{\circ} \mathrm{C}$. These results concur well with the previous discussion of the results of Fig. 4 in section 3.2. The activation energies calculated from $\ln (\sigma \mathrm{T})$ vs. $1000 / \mathrm{T}$ plots are effectively equal for both atmospheres and are $1.36 \mathrm{eV}$ for hole conduction, $0.86 \mathrm{eV}$ for oxygen vacancy conduction and $0.59 \mathrm{eV}$ for proton conduction. The activation energies for proton and oxygen vacancy conductions are in the range previously reported for barium cerates and barium zirconates, albeit toward the higher end, while the activation energy of hole conduction is slightly higher than that typically reported for such materials [9,27,31,32]. The high activation energies recorded may be due to the low sintering temperature used in the current work and the corresponding contribution of a high volume fraction of grain boundaries that may hinder mobility [9].

Fig. 9 shows the transference numbers as a function of temperature at the water vapor partial pressure of $0.033 \mathrm{~atm}$. In a nitrogen atmosphere, ion conductivity is dominant over the 
whole temperature range. Conversely, in oxygen atmosphere, transition from ionic conductivity to hole conductivity is observed between 600 to $650^{\circ} \mathrm{C}$. The ionic conductivity is shown to be dominated by proton conductivity in both oxygen and nitrogen atmospheres.

\section{Conclusions}

Partial conductivities of protons, oxygen vacancies and electron holes were calculated for $\mathrm{Ba}_{0.85} \mathrm{~K}_{0.15} \mathrm{ZrO}_{3-\delta}$ based on a typical defect model derived for protonic ceramic materials that contain an acceptor dopant of single effective negative charge, by measuring total conductivity in different partial pressure of oxygen and water vapor in the temperature range of $550-700^{\circ} \mathrm{C}$. The calculated total conductivity was in good agreement with the experimental results measured in different gas compositions. It was shown that P-type conduction was dominant in dry and oxidative atmospheres. By increasing water vapor pressure and decreasing oxygen pressure, protonic contributions to total conductivity increased and a transition from hole dominated to proton dominated conduction was observed. The ionic conduction corresponded to almost pure proton conduction in the studied temperature range. The calculated activation energies for hole, oxygen vacancy and proton were $1.36 \mathrm{eV}, 0.86 \mathrm{eV}$ and $0.59 \mathrm{eV}$, respectively. The standard solution enthalpy for water was $-90 \mathrm{~kJ} / \mathrm{mol}$; a value that is very close to that reported for $\mathrm{BaZr}_{0.85} \mathrm{Y}_{0.15} \mathrm{O}_{3-\delta}$.

\section{Acknowledgments}

The authors acknowledge financial support from the FCT, FEDER and COMPETE, PTDC/CTM/100412/2008, PTDC/CTM/105424/2008, and FCT Doctoral Research grants SFRH/BD/80949/2011 and SFRH/BD/76738/2011. 


\section{References}

[1] H. Iwahara, T. Esaka, H. Uchida, N. Maeda, Solid State Ionics, 3-4 (1981), p. 359

[2] H. Iwahara, H. Uchida, N. Maeda, Journal of Power Sources, 7 (1982), p. 293

[3] H. Iwahara, Solid State Ionics, 28-30 (1988), p. 573

[4] T. Kobayashi, K. Abe, Y. Ukyo, H. Matsumoto, Solid State Ionics, 138 (2001), p. 243

[5] K. D. Kreuer, S. Adams, W. Munch, A. Fuchs, U. Klock, J. Maier, Solid State Ionics, 145 (2001), p. 295.

[6] Y. Yamazaki, R. Hernandez-Sanchez, S. M. Haile, Chemistry of Materials, 21 (2009), p. 2755.

[7] K. D. Kreuer, Solid State Ionics, 97 (1997), p. 1.

[8] T. Norby, M. Wideroe, R. Glockner, and Y. Larring, Dalton transactions, [19] (2004), p.3012.

[9] A. S. Patnaik, A. V. Virkar, Journal of Electrochemical Society, 153 (2006), p. A1397.

[10] X. Xu, S. Tao, J. T. S. Irvine, Journal of solid state chemistry, 183 (2010), p. 93.

[11] J. Nowotny, C. C. Sorrell, Electrical Properties of Oxide Materials, Trans Tech Publication Ltd (1997).

[12] D. Pérez-Coll, G. Heras-Juaristi, D. P. Fagg, G. C. Mather, J.Power Sources 245(2014), p. 445

[13] H. K. Bentzer, N. Bonanos, J. W. Phair, Solid State Ionics 181 (2010), p.249

[14] M. H. Hebb, The Journal of Chemical physics, 20 (1952), p.185.

[15] C. Wagner, in Proceedings of International Conference on Electrochemical Thermodynamic Kinetics, Butterworth, London (1957), p.361.

[16] W. Weppner and R. A. Huggins, Annual Review of Materials Science, 8 (1978), p. 369.

[17] H. Rickert, Electrochemistry of Solids, Springer, Berlin (1982), p. 102.

[18] I. Riess, Solid State Ionics, 44 (1991), p. 199.

[19] I. Riess, Solid State Ionics, 44 (1991), p. 207.

[20] Z. Sherafat, I. Antunes, C. Almeida, J. R. Frade, M. H. Paydar, G. C. Mather, D. P. Fagg, Dalton Transactions, 43 (2014), p.9324.

[21] I. Antunes, A.Brandão, F.M.Figueiredo, J.R.Frade, J.Grácio, D.P.Fagg, J.Solid State Chem. 182 (2009), p. 2149.

[22] D. K. Lim, C. J. Park, , M. B. Choi, C. N. Park, S. J. Song, International Journal of Hydrogen Energy, 35 (2010), p. 10624.

[23] H. D. Baek, Solid State Ionics, 110 (1998), p. 255.

[24] J.R. Frade, Solid State Ionics 78 (1995), p. 87.

[25] J. I. Langford, D. Louër, P. Scardi, Journal of Applied Crystallography, 33 (2000), p.964. 
[26] R. D. Shannon, C. T. Prewitt, Acta Crystallographica Section B, 25 (1969), p. 925.

[27]S. J. Song, E. D. Wachsman, S. E. Dorris, U. Balachandran, Journal of TheElectrochemical Society, 150 (2003), p. A790.

[28] H. Uchida, N. Maeda, H. Iwahara, Solid State Ionics, 11 (1983), p.117.

[29] K. D. Kreuer, Solid State Ionics, 125 (1999), p. 285.

[30] K. D. Kreuer, Annual Review of Materials Research, 33 (2003), p. 333.

[31] H. Iwahara, T. Yajima, T. Hibino, K. Ozaki, H. Suzuki, Solid State Ionics, 61(1993), p. 65 .

[32] W. Wang, A. V. Virkar, Journal of Power Sources, 142 (2005), p.1 


\section{Table and Figure captions}

Table 1- The slopes and intercepts of $\sigma_{\text {tot }}$ vs. $\mathrm{P}_{\mathrm{O}_{2}}^{1 / 4}$ obtained by linear fitting.

Table 2- Calculated $\sigma_{\mathrm{OH}_{\mathrm{O}}^{*}}^{*} ; \sigma_{\mathrm{V}_{\mathrm{O}}}^{*} ; \sigma_{\mathrm{p}}^{*} ; \mathrm{K}_{\mathrm{w}}$ and $\alpha$ at different temperatures.

Fig. 1- The X-ray diffraction pattern of the $\mathrm{Ba}_{0.85} \mathrm{~K}_{0.15} \mathrm{ZrO}_{3-\delta}$ sample, (a) obtained by room temperature mechanosynthesis, (b) after sintering the pelletized powder to $1300^{\circ} \mathrm{C}$ for $5 \mathrm{hrs}$ in a sealed container.

Fig. 2 - SEM micrograph of a fracture surface of the $\mathrm{Ba}_{0.85} \mathrm{~K}_{0.15} \mathrm{ZrO}_{3-\delta}$ sample sintered at $1300^{\circ} \mathrm{C}$

Fig. 3 - Typical EIS plots measured at $450^{\circ} \mathrm{C}$ in wet oxygen and wet nitrogen atmospheres and corresponding equivalent circuit. Inset shows typical impedance response measured at lower temperatures with relevant equivalent circuit.

Fig. 4 -Total conductivity of $\mathrm{BKZ}$ as a function of temperature under constant $\mathrm{P}_{\mathrm{O}_{2}}$ at various water vapor pressures: (a) oxygen conditions, and (b) nitrogen conditions.

Fig. 5 -Total conductivity of $\mathrm{BKZ}$ vs. $\mathrm{P}_{\mathrm{O}_{2}}^{1 / 4}$ under constant $\mathrm{P}_{\mathrm{H}_{2} \mathrm{O}}$ at various temperatures: (a) dry condition (b) $\mathrm{P}_{\mathrm{H}_{2} \mathrm{O}}=0.0016 \mathrm{~atm}$, and (c) $\mathrm{P}_{\mathrm{H}_{2} \mathrm{O}}=0.033$ atm.

Fig. 6 - The equilibrium constant of hydration as a function of temperature.

Fig. 7 - Total and partial conductivities in nitrogen atmosphere and $650^{\circ} \mathrm{C}$. Experimental data are shown by points in the graph.

Fig. 8 -Total and partial conductivities of $\mathrm{BKZ}$ vs.reciprocal temperature at $\mathrm{P}_{\mathrm{H}_{2} \mathrm{O}}=0.033 \mathrm{~atm}$, (a) oxygen atmosphere and (b) nitrogen atmosphere.

Fig. 9 - Transference number vs. $1000 / \mathrm{T}$ at $\mathrm{P}_{\mathrm{H}_{2} \mathrm{O}}=0.033 \mathrm{~atm}$, (1) $\mathrm{t}_{\text {ionic }}$ and $\mathrm{t}_{\mathrm{p}}$ and $(2) \mathrm{t}_{\mathrm{OH}} \cdot / t_{\text {ionic }}$ and $t_{\mathrm{V}_{\mathrm{O}}} / t_{\text {ionic }}:$ (a) oxygen atmosphere and (b) nitrogen atmosphere. 


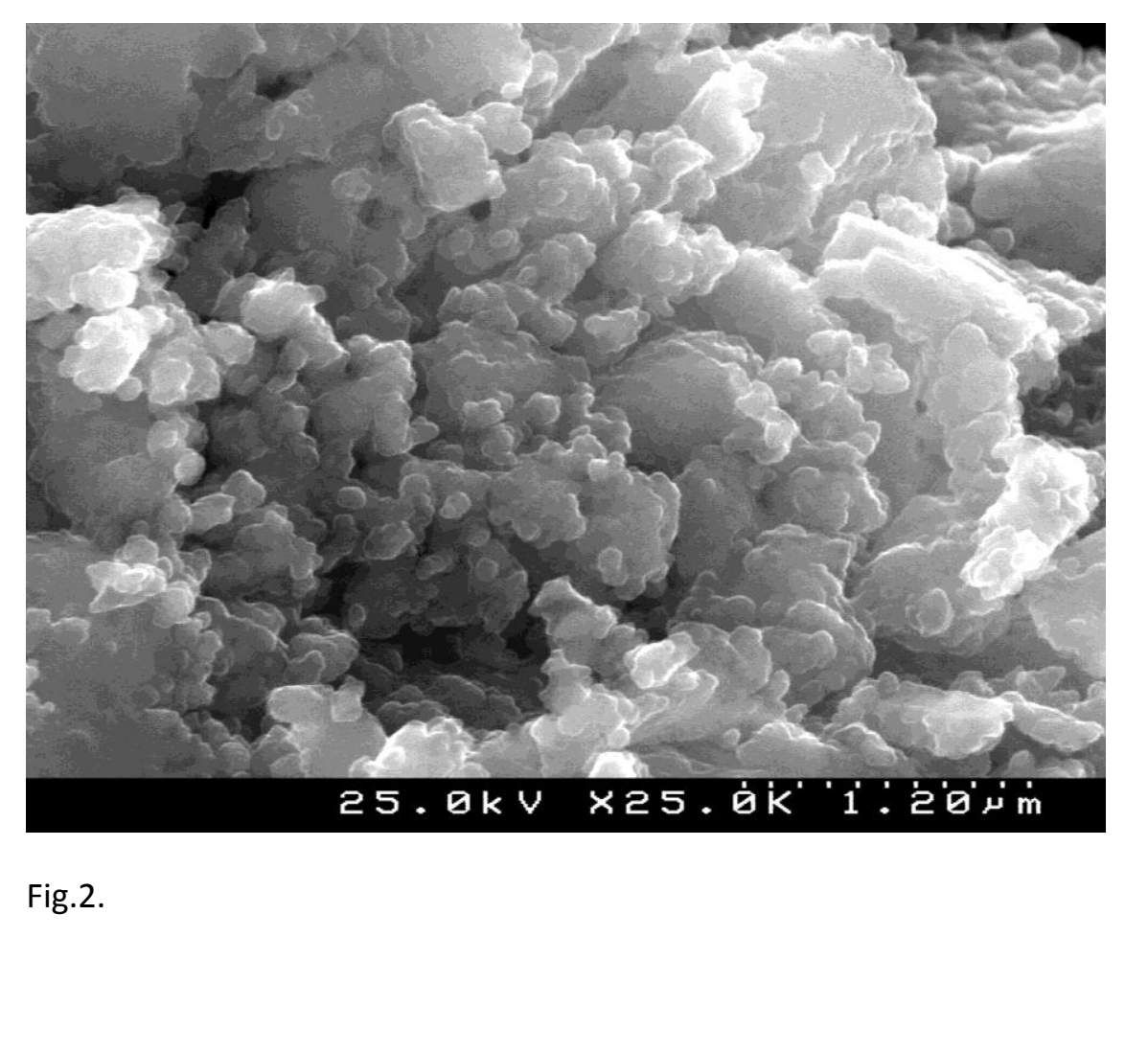

Figure
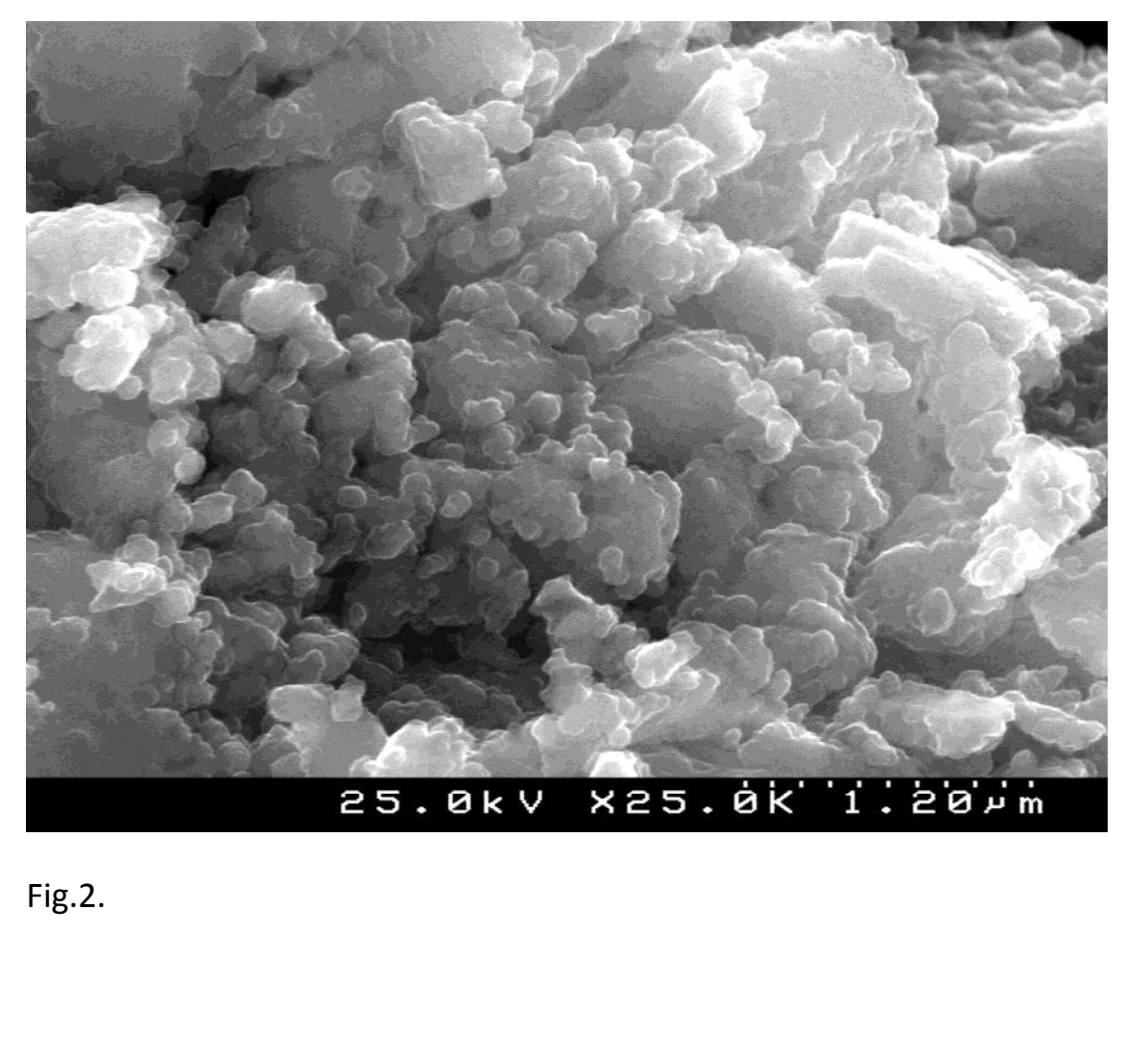

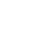

\begin{abstract}
Fig. 2.

.

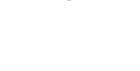

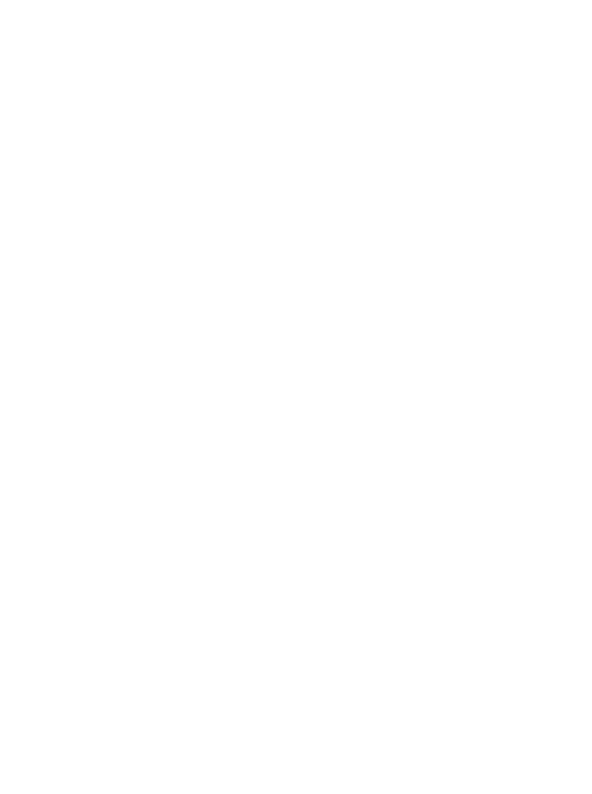
(1)
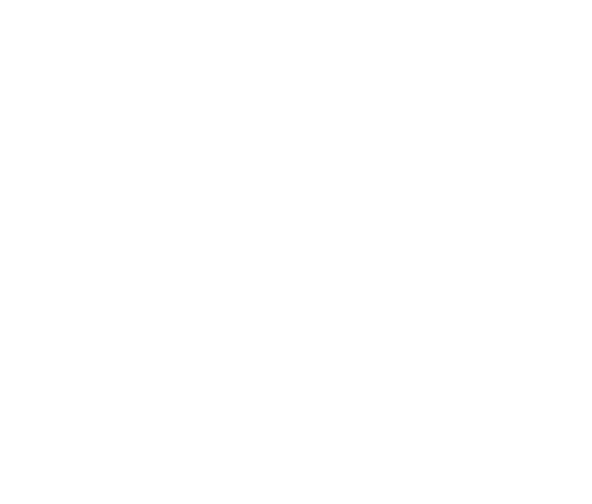

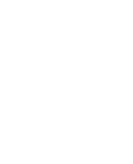

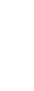

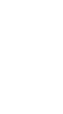
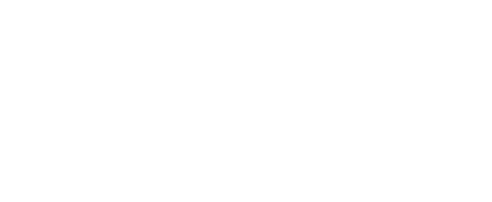


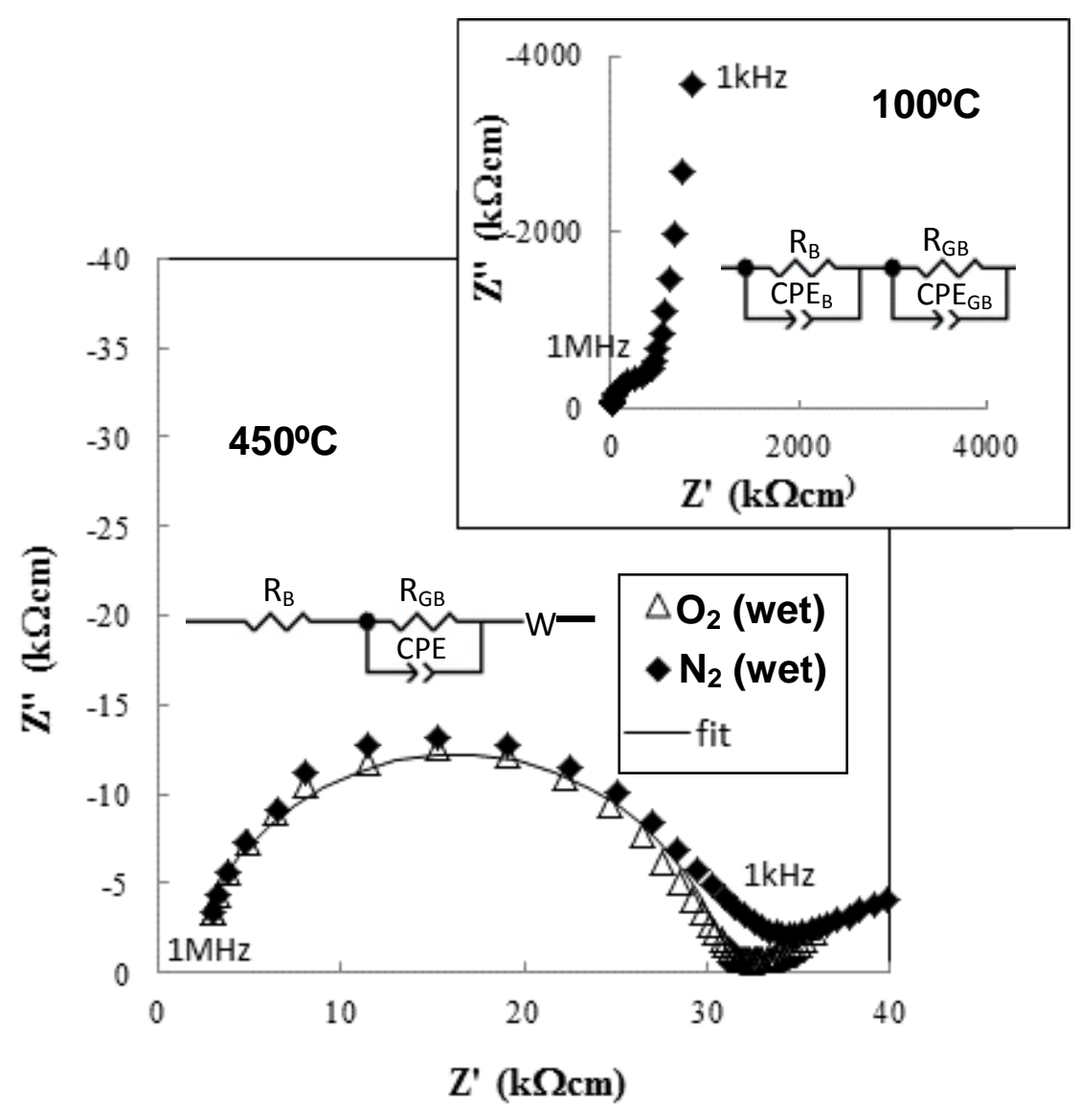

Fig 3 

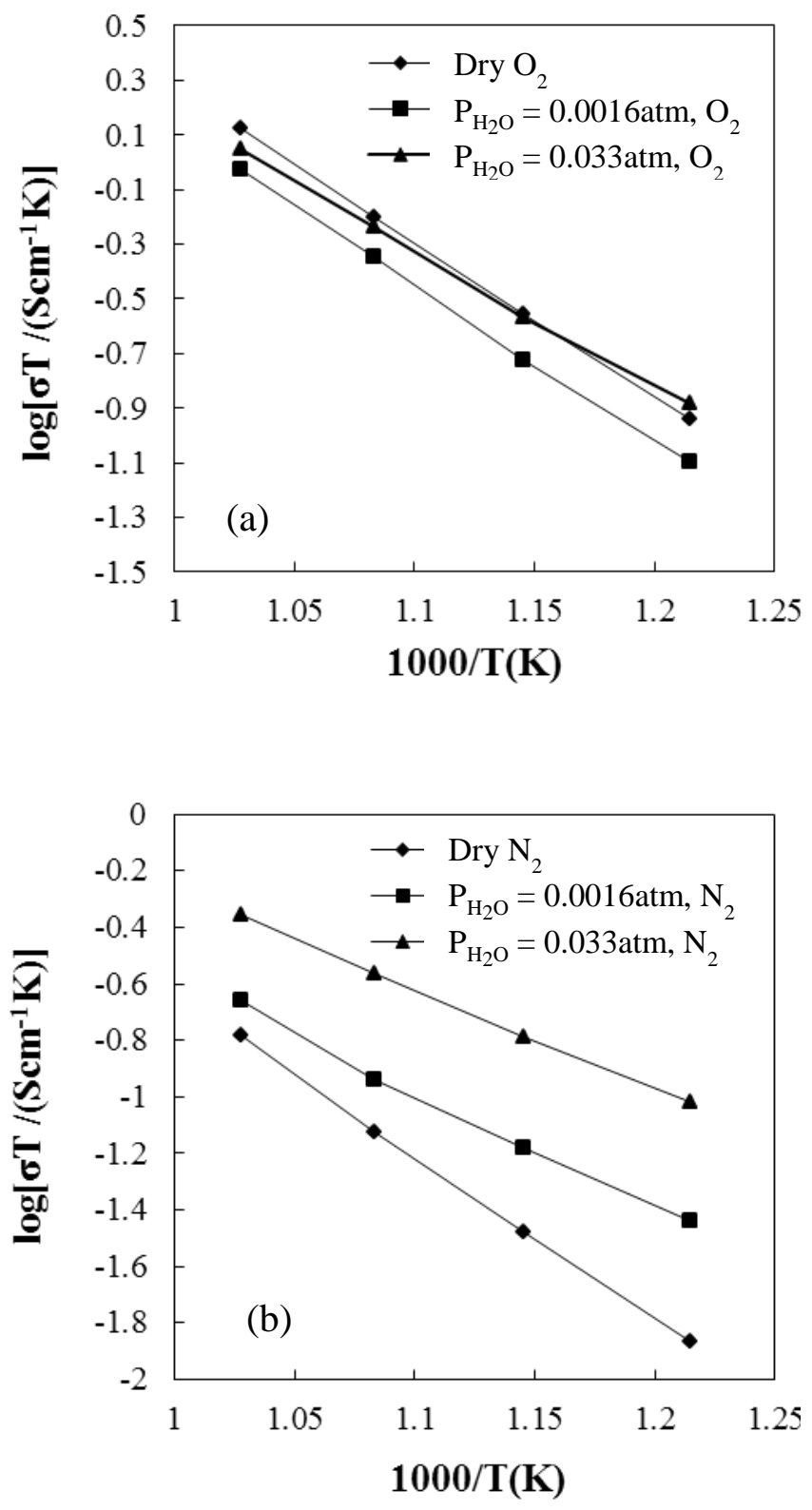

Fig. 4 

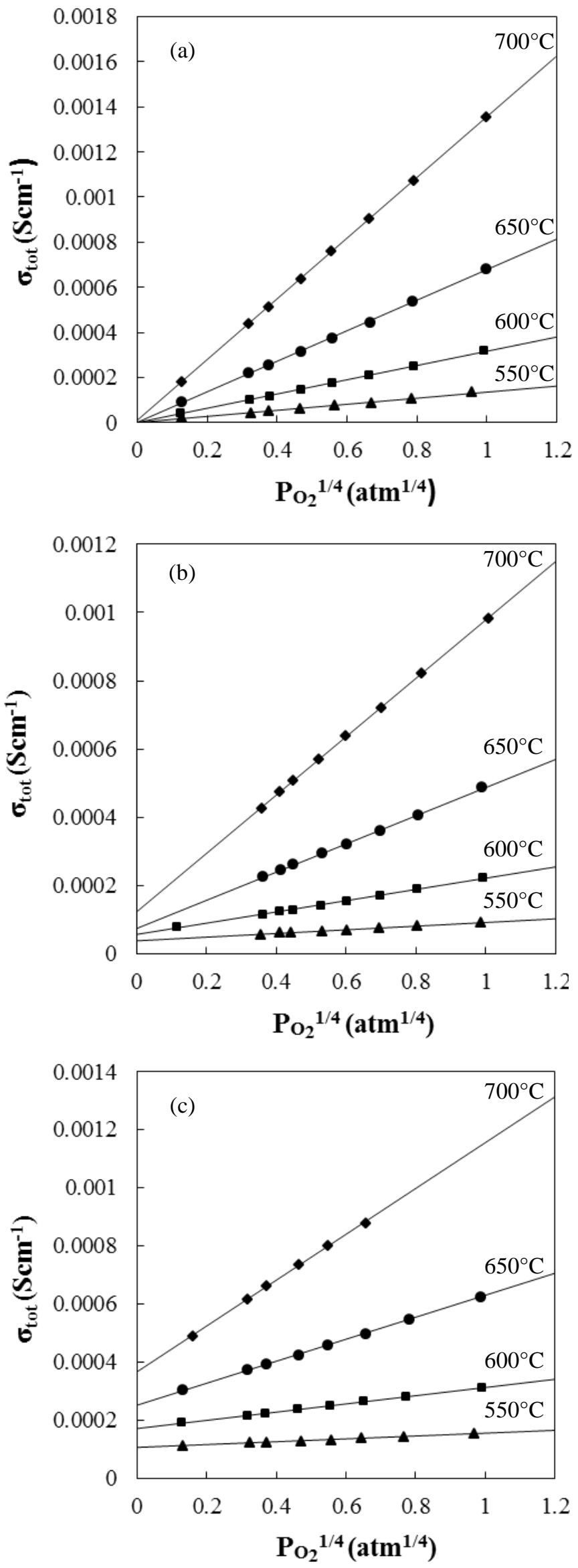

Fig. 5 


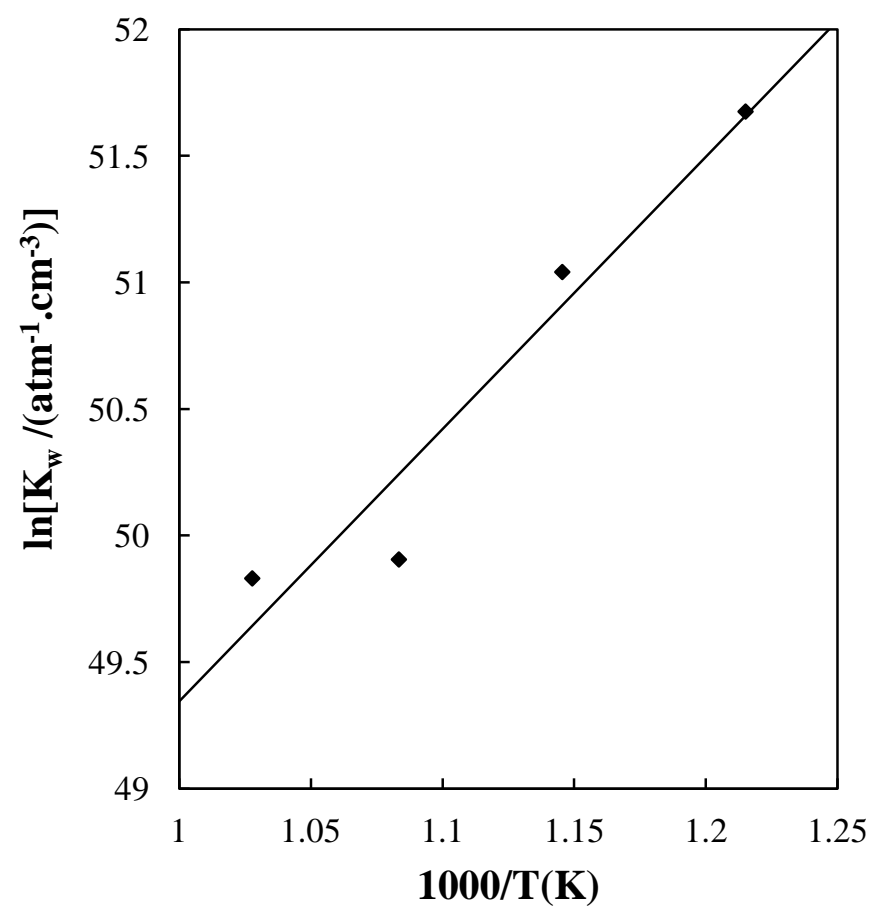

Fig. 6 


\section{Figure7}

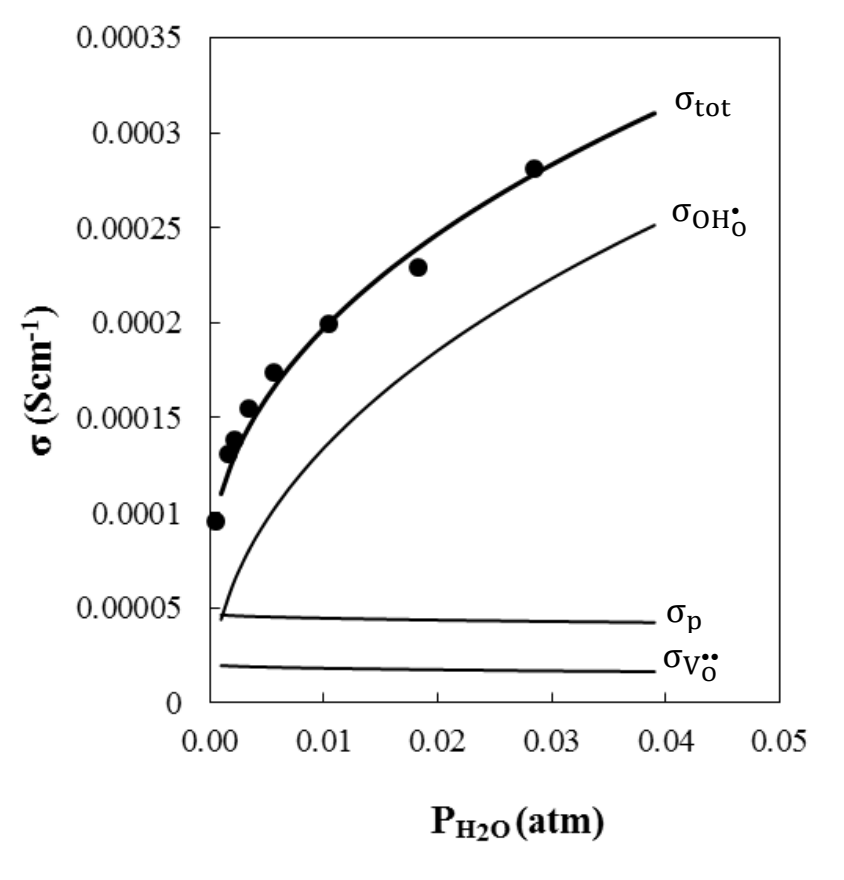

Fig. 7

(1) 0.0002

7

7
cra

(
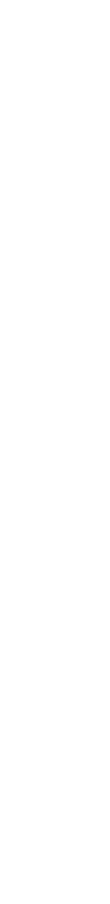

(2)
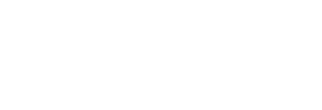

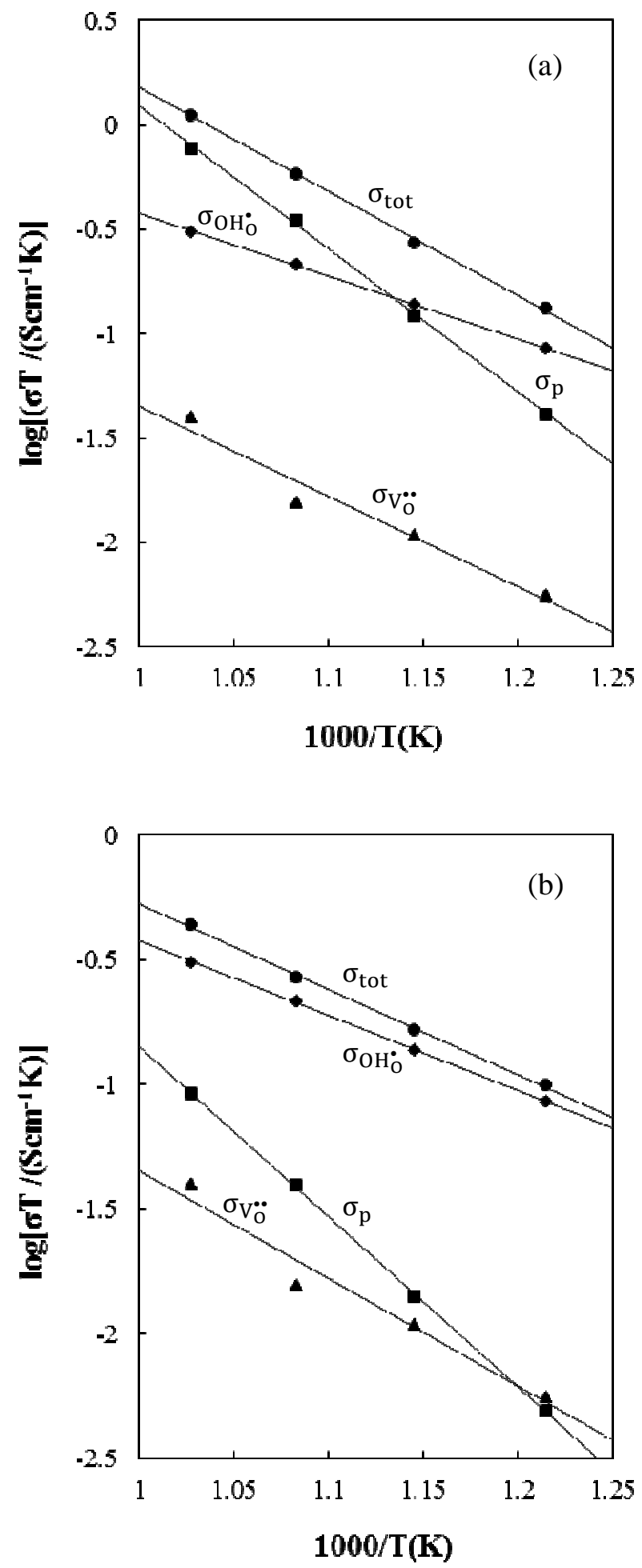

Fig. 8 

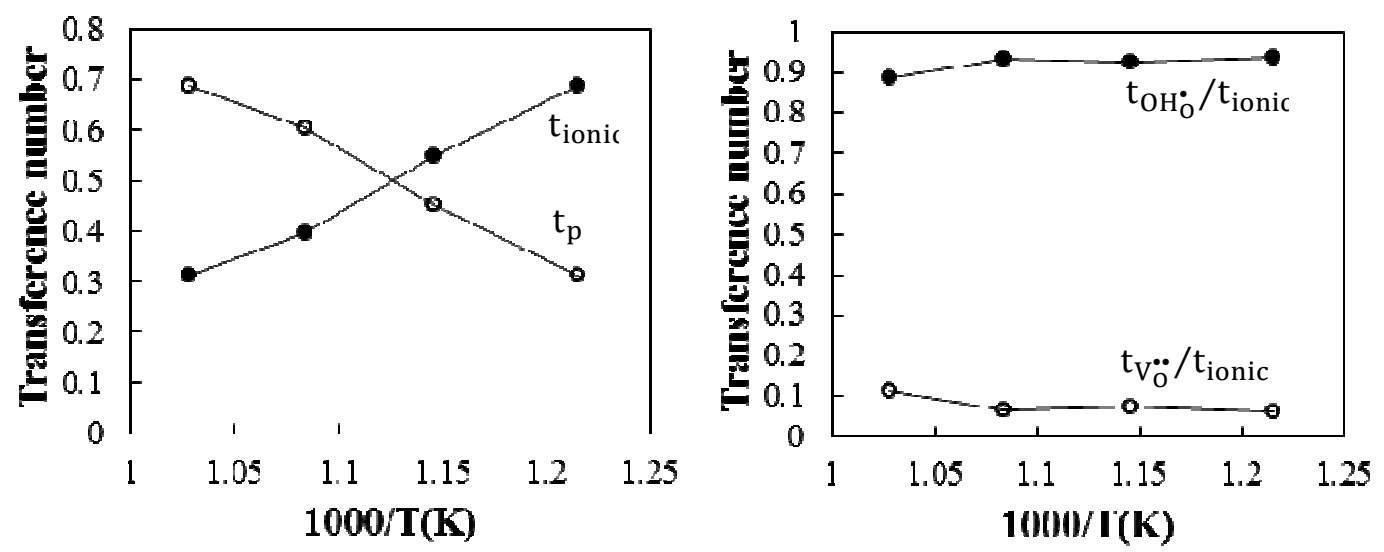

(a)
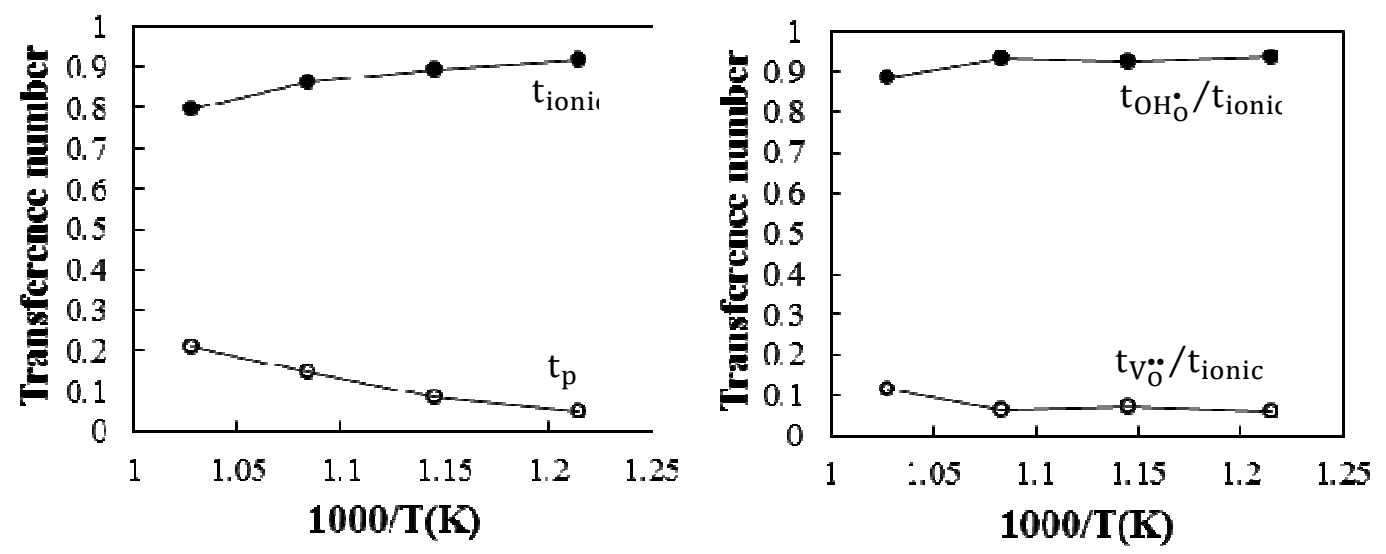

(b)

Fig. 9 
Table 1

\begin{tabular}{|c|c|c|c|c|c|c|}
\hline & \multicolumn{2}{|c|}{ dry } & \multicolumn{2}{|c|}{$P_{\mathrm{H}_{2} \mathrm{O}}=0.00166 \mathrm{~atm}$} & \multicolumn{2}{|c|}{$P_{\mathrm{H}_{2} \mathrm{O}}=0.033 \mathrm{~atm}$} \\
\hline $\begin{array}{c}\text { Temperature } \\
\left({ }^{\circ} \mathrm{C}\right)\end{array}$ & $\begin{array}{c}\text { slope(b) } \\
\left(\mathrm{Scm}^{-1} \mathrm{~atm}^{-1 / 4}\right)\end{array}$ & $\begin{array}{c}\text { intercept(a) } \\
\left(\mathbf{S c m}^{-1}\right)\end{array}$ & $\begin{array}{c}\text { slope(b) } \\
\left(\mathrm{Scm}^{-1} \mathrm{~atm}^{-1 / 4}\right)\end{array}$ & $\begin{array}{c}\text { intercept }(a) \\
\left(\mathrm{Scm}^{-1}\right)\end{array}$ & $\begin{array}{c}\text { slope(b) } \\
\left(\mathrm{Scm}^{-1} \mathrm{~atm}^{-1 / 4}\right)\end{array}$ & $\begin{array}{c}\text { intercept(a) } \\
\left(\mathrm{Scm}^{-1}\right)\end{array}$ \\
\hline 550 & 0.00014 & 0 & 0.00006 & 0.000037 & 0.00005 & 0.00011 \\
\hline 600 & 0.00032 & 0 & 0.00016 & 0.000056 & 0.00014 & 0.00017 \\
\hline 650 & 0.00068 & 0 & 0.00041 & 0.000075 & 0.00038 & 0.00025 \\
\hline 700 & 0.00135 & 0.00001 & 0.00085 & 0.000123 & 0.00079 & 0.00036 \\
\hline
\end{tabular}


Table 2

\begin{tabular}{|c|c|c|c|c|c|}
\hline $\begin{array}{c}\text { Temperature } \\
\left({ }^{\circ} \mathbf{C}\right)\end{array}$ & $\begin{array}{c}\boldsymbol{\alpha} \\
(\mathbf{a t m})\end{array}$ & $\begin{array}{c}\mathbf{K}_{\mathbf{w}}{ }^{-3} \\
\left(\mathbf{a t m}^{-\mathbf{c m}}\right)\end{array}$ & $\boldsymbol{\sigma}_{\mathbf{p}}^{*}\left(\mathbf{S c m}^{-\mathbf{1}}\right)$ & $\boldsymbol{\sigma}_{\mathbf{O H}_{\mathbf{O}}^{*}}^{*}\left(\mathbf{S c m}^{-\mathbf{1}}\right)$ & $\boldsymbol{\sigma}_{\mathbf{\mathbf { v } _ { \mathbf { o } } ^ { * }}}^{*}\left(\mathbf{S c m}^{-\mathbf{1}}\right)$ \\
\hline $\mathbf{5 5 0}$ & 0.59 & $2.76733 \mathrm{E}+22$ & $6.32058 \mathrm{E}-05$ & 0.000244 & $1.08 \mathrm{E}-05$ \\
\hline $\mathbf{6 0 0}$ & 1.112 & $1.46828 \mathrm{E}+22$ & 0.000166184 & 0.000442 & $1.76 \mathrm{E}-05$ \\
\hline $\mathbf{6 5 0}$ & 3.462 & $4.71613 \mathrm{E}+21$ & 0.000418909 & 0.000846 & $2.04 \mathrm{E}-05$ \\
\hline $\mathbf{7 0 0}$ & 3.731 & $4.3761 \mathrm{E}+21$ & 0.000867784 & 0.00117 & $4.94 \mathrm{E}-05$ \\
\hline
\end{tabular}

